\title{
SLL1-ZH Regulates Spikelets Architecture and Grain Yield in Rice
}

\author{
Lianping Sun ${ }^{+} \mathbb{C}$, Jingxin Wang ${ }^{\dagger}$, Xiaoxia Wen $^{\dagger}$, Zequn Peng, Daibo Chen, Yingxin Zhang, Shihua Cheng, \\ Liyong Cao and Xiaodeng Zhan *
}

check for

updates

Citation: Sun, L.; Wang, J.; Wen, X.; Peng, Z.; Chen, D.; Zhang, Y.; Cheng, S.; Cao, L.; Zhan, X. SLL1-ZH

Regulates Spikelets Architecture and Grain Yield in Rice. Agriculture 2021, 11, 1162. https://doi.org/10.3390/ agriculture11111162

Received: 21 October 2021

Accepted: 13 November 2021

Published: 18 November 2021

Publisher's Note: MDPI stays neutral with regard to jurisdictional claims in published maps and institutional affiliations.

Copyright: (c) 2021 by the authors. Licensee MDPI, Basel, Switzerland. This article is an open access article distributed under the terms and conditions of the Creative Commons Attribution (CC BY) license (https:// creativecommons.org/licenses/by/ $4.0 /)$.
Key Laboratory for Zhejiang Super Rice Research, Chinese National Center for Rice Improvement and Stat Key Laboratory of Rice Biology, China National Rice Research Institute, Hangzhou 311402, China; sunlianping@caas.cn (L.S.); jingxinwang2017@163.com (J.W.); 18883966700@163.com (X.W.); 13720149899@163.com (Z.P.); chendaibo@caas.cn (D.C.); zyxrice@163.com (Y.Z.); chengshihua@caas.cn (S.C.); caoliyong@caas.cn (L.C.)

* Correspondence: zhanxiaodeng@caas.cn; Tel.: +86-571-6337-0338

+ These authors contributed equally to this work.

\begin{abstract}
The spikelet developmental processes that control structure and floral organ identity play critical roles in rice grain yield formation. In this study, we characterized a novel rice mutant, SLL1$\mathrm{ZH}$, which exhibits a variety of defective agronomic characters, including semi-dwarf, rolling leaf, deformed panicles, and reduced grains production. Morphological analysis also revealed that the SLL1-ZH mutant shows numerous defects of floral organs, such as cracked glumes, hooked and thin lemmas, shrunken but thickened paleas, an indeterminate number of stamens and stigmas, and heterotopic ovaries. Map-based cloning identified a single nucleotide substitution (C to $\mathrm{G}$ ) in the first exon of LOC_Os09g23200 that is responsible for the SLL1-ZH phenotype. In addition, qPCR analysis showed a significant change in the relative expression of SLL1-ZH in the mutant during inflorescence differentiation and in the different floral organs. Transcription of rice floral organ development-related factors also changed significantly in the mutant. Therefore, our results suggested that SLL1-ZH plays a great role in plant growth, spikelet development, and grain yield in rice.
\end{abstract}

Keywords: rice; grain yield; floral organ; SLL1-ZH; map-based cloning

\section{Introduction}

Rice (Oryza sative L.), a model monocotyledonous plant species used in molecular biology and functional genomics research, has a unique and representative floral architecture in the grass family (Poaceae). The spikelet is a special type of floret present in rice and other gramineous crops. Spikelets can contain one or more florets; the morphogenesis of floral organs in rice is distinct from those of model dicots like Arabidopsis thaliana and Antirrhinum majus and is of great significance to yield formation. A mature rice spikelet contains two pairs of sterile glumes, one pair of rudimentary glumes which have been reduced to spikelet supports, and one pair of empty glumes. It also contains one floret, which includes one lemma and one palea, six stamens, a pistil with two stigmas and two lodicules at its base, and one ovary going from the external to the internal whorls [1-3].

The ABC to ABCDE model, which is based on genetic and functional studies of flower development in dicot species, such as Arabidopsis t. and Antirrhinum m., has been gradually established and widely recognized [4-8]. The unique spikelet properties and inflorescence differentiation and development in rice are also regulated by a series of transcription factors and other genes. In recent decades, numerous genes have been reported to regulate floral organ identity and development in rice. Through comparative morphological analysis, biological function, and homologous alignment between rice and A. thaliana, we found that the dicotyledon ABCDE model is at least partially applicable to rice floral 
development, and that the regulators can also be divided into the same five sub-groups [9]. Rice MADS genes thus have been divided into five classes on the basis of the ABCDE model: A-class (AP1/Ful-like homologs) genes includes OsMADS14 (RAP1A), OsMADS15 (DEP1), OsMADS18 and OsMADS20 [10-15]; the B-class (PI- and AP3- like homologs) genes include SUPERWOMEN1 (OsMADS16), OsMADS2 and OsMADS4 [16,17]; the C-class (AGAMOUS homologs) genes are OsMADS3 and OsMADS58 [18,19]; the D-class genes are OsMADS13 and OsMADS21 [20,21] and the E-class genes include LEAFY HULL STERILE1/OsMADS1/OHMS1, OsMADS5, OsMADS7, OsMADS8 and OsMADS34 [22-26]. Quite a few non-MADS-box genes have also been reported to determine inflorescence development and specify floral organ identities. The Arabidopsis t. YABBY family homolog DROOPING LEAF $(D L)$ also acts as a B-class transcription factor to regulate the number of stamens and stigmas, as well as carpel specification [16,27]. The CLAVATA genes FON1, FON2, and FON4 were also reported to regulate the size of the inflorescence meristem and floral organ numbers in rice [28-31]. The EMF1-like protein DFO1/CCP1 determines rice floral organ identity especially in palea specialization and development together with PcG proteins to maintain the H3K27me3-mediated epigenetic repression at the OsMADS58 locus [32,33]. OsFDML1 and OsFDML2, the homologs of the Arabidopsis SUPPRESSOR OF GENE SILENCING3-like gene FDM1, regulates floral organ development mainly promoted by OsMADS6 at their putative CArG motifs in the promoter region, and especially determine palea and carpels identity, the number of stigmas and meristem indeterminacy [34]. OsPEX5/DFO2 regulates rice spikelet development by mediating peroxisomal import of OsOPR7 into jasmonic acid biosynthesis [35]. The $\mathrm{C} 2 \mathrm{H} 2$ zinc finger gene NSG1 maintains floral organ identities by interacting with TPRs to regulate the expression levels of OsMADS1, MFO1, DL, and G1 [36]. OsPID determines stamen, stigma, and ovule initiation through interactions with NPYs, OsPIN1a, OsPIN1b, OsMADS16, and LAX1/LAX2, and it also participates in the maintenance of the floral meristem through auxin signaling [37-39].

The developmental processes that control the identities and morphologies of developing flower organs directly influence plant growth, spikelet fertility, grain size, and yield formation. Mutation of alternative splicing sites within the K-domain of OsMADS1 caused open hull and tridentate lemma phenotypes, semi-sterility of pollen grains, completely sterile spikelets and aberrant grain shape [26,40]. A recessive mutation in OsMADS34 resulted in not only long sterile lemmas and defective florets, but also a low yield formation phenotype that included short panicles, smaller grains, and lower seed-setting rate [41]. The ubiquitin-specific protease gene $F L A$ controls development of rice spikelet structure and chlorophyll accumulation, the fla mutant exhibited deformed spikelets, zebra striped and bleached leaves, rolled flag leaves, abnormal seeds, and low seed set [42]. The MYB transcription factor $S L L 1 / A H 2$ regulates both leaf abaxial cell development and spikelets differentiation, mutation of $S L L 1 / A H 2$ produces rolled leaves with increased chlorophyll content, smaller grains, and lower grain quality $[43,44]$. TH1/BSG1/AFD1/BH1, a gene which encodes a DUF640 domain-like protein, affects a series of processes during the rice growth stages. Recessive th1/bsg1/afd1/bh1 mutants display multiple anomalies such as dwarfism, long panicles, beak-shaped hulls, beak-shaped triangular grains, a low seed setting rate, and reduced grain yield [45-47]. Many recessive mutations in genes related to flower development cause spikelet deformity, a decline in the seed setting rate, and reduced grain yield, as mentioned above, but there are still a few genes mutations that have positive effects on yield formation. Ectopic expression of LF1/OsHB1, a gene that encodes an HD-ZIP III transcription factor, can produce plants with three-florets spikelet that increases the grain number per panicle, resulting in yield improvement, by regulating its own ectopic expression state [48]. The lipase gene EG1/DF1 not only specifies sterileglume identity and the determination of flower meristem, but also promotes floret number. Both the $d f 1-1$ and $d f 1-2$ mutants had two florets within a single spikelet $[49,50]$. Precise design and reasonable combination of these mutations could have potential utilization value for genetic improvement of high-yield rice cultivars in breeding programs. 
In this study, we identified a new SLL1/ AH2 allelic mutant (SLL1-ZH) that shows a series of defects in plant growth, floret development, and yield formation from our indica rice (Zhonghui8015, wild-type, WT) ethylmethylsulfone (EMS) mutation library. Candidate gene analysis indicated that the mutated LOC_Os09g23200 gene carried a single base pair (bp) substitution, resulting in a corresponding altered protein. A complementation test demonstrated that LOC_OsO3g23200 is indeed SLL1-ZH, and transcript analysis revealed the critical role of SLL1-ZH in floral organ differentiation and development.

\section{Materials and Methods}

\subsection{Rice Materials and Plant Growth Conditions}

The SLL1-ZH mutant was identified from our EMS mutant Zhonghui8015 (Zh8015, ssp. indica) library [51]. The mutant exhibited genetic stability both when grown under natural LD condition (Lingshui, Hainan) and natural SD condition (Zhejiang, Fuyang). The sll1-zh mutant was used as the pollen recipient in crosses. Genetic population construction and field planting were as described in previous reports [26,51].

\subsection{Phenotyping and Morphological Analysis}

Plant materials, including rice plants, leaves, spikelets, and seeds were collected and photographed as described previously [26,51,52]. For scanning electron microscopy (SEM) observation of flower organ primordium differentiation and development, fresh inflorescences of different lengths were sampled and processed as described previously [50].

\subsection{Molecular Cloning of SLL1-ZH}

Plants with the sll1-zh phenotype in the $\mathrm{F}_{2}$ population were selected for gene mapping. Newly designed InDel markers that are polymorphic between the two parents (SLL1-ZH and 02428) were selected for fine mapping (Table S3). DNA extraction from all genetic materials, DNA fragment amplification, and candidate genes prediction and analysis were processed as described previously $[26,51,52]$.

\subsection{Genetic Complementation of the SLL1-ZH Mutant}

For complementation, the sll1-ZH-CF/sll1-ZH-CR primer pair (Supplementary Table S3) were used to amplify the complementary gene, $S L L 1-Z H$, from the WT. These consisted of an 11.1-kb genomic fragment that included a 3, 139 bp promoter region, a 6, 838 bp ORF, and a 1, $081 \mathrm{bp}$ terminator. The $p$ Com-SLL1-ZH fragment was cloned into the plasmid pCAMBIA1300 (CAMBIA; hygromycin resistance) between the EcoR I and BamH I sites, and the recombinant vector plasmid was then introduced into the SLL1-ZH mutant using Agrobacterium tumefaciens-mediated transformation after verification by DNA sequencing. Positive transgenic pCOM-SLL1-ZH plants were selected by functional verification.

\subsection{RNA Extraction and qPCR Analysis}

Young panicles at early developmental stages and different separate floral organs from mature spikelets at anthesis were sampled for RNA extraction and qPCR from the SLL1-ZH mutant and WT plants. This analysis examined the relative expression of SLL1-ZH (Table S3 and https:/ / biodb.swu.edu.cn/qprimerdb/download-primers, accessed on 15 January 2020) and several floral organ identity genes [24,33,35] using the thermal cycler profile as previously described [52]. The ubiquitin (UBQ) gene was used as the internal gene expression control in this study. The operation and data analysis for all experiments were carried out as described in previous reports [26,51-53].

\section{Results}

\subsection{SLL1-ZH Affects Both Plant Architecture and Grain Yields}

To further understand the molecular mechanism of rice growth and reproductive development, we identified a semi-dwarf mutant, SLL1-ZH, with floral organ dysplasia, in our mutant library. Compared with the WT, the SLL1-ZH mutant exhibited semi- 
dwarf stature (Figure 1A), rolled leaves (Figure S1A,B), smaller and misshapen panicles (Figure 1B-D), and a low seed setting rate (Figure 1E). Observation of adixial sections of the transversal surface of leaves in the WT and SLL1-ZH mutant revealed that SLL1-ZH mutant had sharper mid-veins (Figure S1C,F) with smaller phloem cells, xylem, and vascular bundle sheath, thinner sclerenchyma layer and mesophyll cells (Figure S1D,E,G,H), and rolling leaf blade margins (Figure S1I,J). The mutant also had smooth lateral veins with smaller phloem cells, xylem, and vascular bundle sheaths, a thinner sclerenchyma layer and mesophyll cells on both sides (Figure S1K,M), and broken small veins with a smaller vascular bundle sheath region and thinner sclerenchyma on both sides (Figure S1L,N). Further classification and observation of seeds between the WT and the SLL1-ZH mutant found that the mutant plant produced shorter and smaller grains with various severe defects, such as cracked glumes, hooked lemmas, olecranoid lemmas and invaginated paleas, crisscross glumes, and shrunken paleas (Figure 1F,G). The investigation of yieldrelated agronomic characters showed that plant height, No. of panicles per plant, No. of spikelets per panicle, seed-setting rate, and thousand grains weight of the SLL1-ZH mutant plants were all significantly reduced compared with the WT (Figure $1 \mathrm{H})$, resulting in an extremely low grain yield in the mutant (Figure $1 \mathrm{H}$ ). When the SLL1-ZH mutant was pollinated by WT and the japonica cultivar 02428 , all $\mathrm{BC}_{1} \mathrm{~F}_{1}$ and $\mathrm{F}_{1}$ plants exhibited normal growth and developmental morphology. Further statistical analysis of plants in the $\mathrm{BC}_{1} \mathrm{~F}_{2}$ and $\mathrm{F}_{2}$ population also confirmed that the $S L L 1-\mathrm{ZH}$ phenotype was regulated by a recessive a pair of recessive karyogenes (Table S1). These results show that the recessive mutation in the SLL1-ZH mutant affects both plant growth and yield formation in rice.

\subsection{Abnormal Floral Organ Identity and Development in the SLL1-ZH Mutant}

In addition to plant architecture and grain shape, another obvious defect in the SLL1$\mathrm{ZH}$ mutant is spikelet morphology, which showed a series of defects in the development of almost all floral organs except for the sterile lemma and lodicules (Figure 2A-H). In a wild-type rice spikelet, one lemma and one palea are tightly linked to form an interlocked structure as the outer whorl of the whole floret (Figure 2A), while most spikelets in the SLL1-ZH mutant exhibited various morphologies such as cracked glumes (Figure 2B), hooked lemmas (Figure 2C) and shrunken paleas (Figure 2C,D). The palea of a small subset parts of SLL1-ZH spikelets were completely trapped within the lemma and were almost invisible (Figure 2D). Closer examination after removing the lemma and palea revealed that the SLL1-ZH spikelets had several defects during floral organ identity determination and development. A WT floret consists of six golden-yellow stamens, one pistil with two expanded pinnate stigmas and one green bulbous ovary at the base (Table 1; Figure 2I). In contrast, the numbers of lemmas/paleas, stamens, stigmas, and ovaries were all varied in the mutant (Table 1; Figure 2F-H). The number of stamens in SLL1-ZH spikelets ranged from three to seven (Table 1) and many of them were light yellow or milky white in color (Figure 2F-H), resulting in the low seed setting rate of SLL1-ZH plants. Notably, most pistils in the SLL1-ZH spikelets had larger bulky stigmas (Figure 2F- $\mathrm{H}, \mathrm{J}, \mathrm{K}$ ), some flowers had two normal stigma and one smaller additional stigmas (Figure 2J,K), and several of them were obviously dwarfed and shriveled (Figure 2L). Interestingly, almost all of the ovaries in SLL1-ZH spikelets were obviously swollen and dilated (Figure 2J-L), and one floret displayed marked proliferation in the innermost whorl; there were two extra ectopic stigma-like organs and one ovary-like organ in addition to several expanded ovule-like cell masses (Figure 2J-L). These results illustrate the non-determinacy and confusion of floral organ identity and organ number in the SLL1-ZH mutant. 

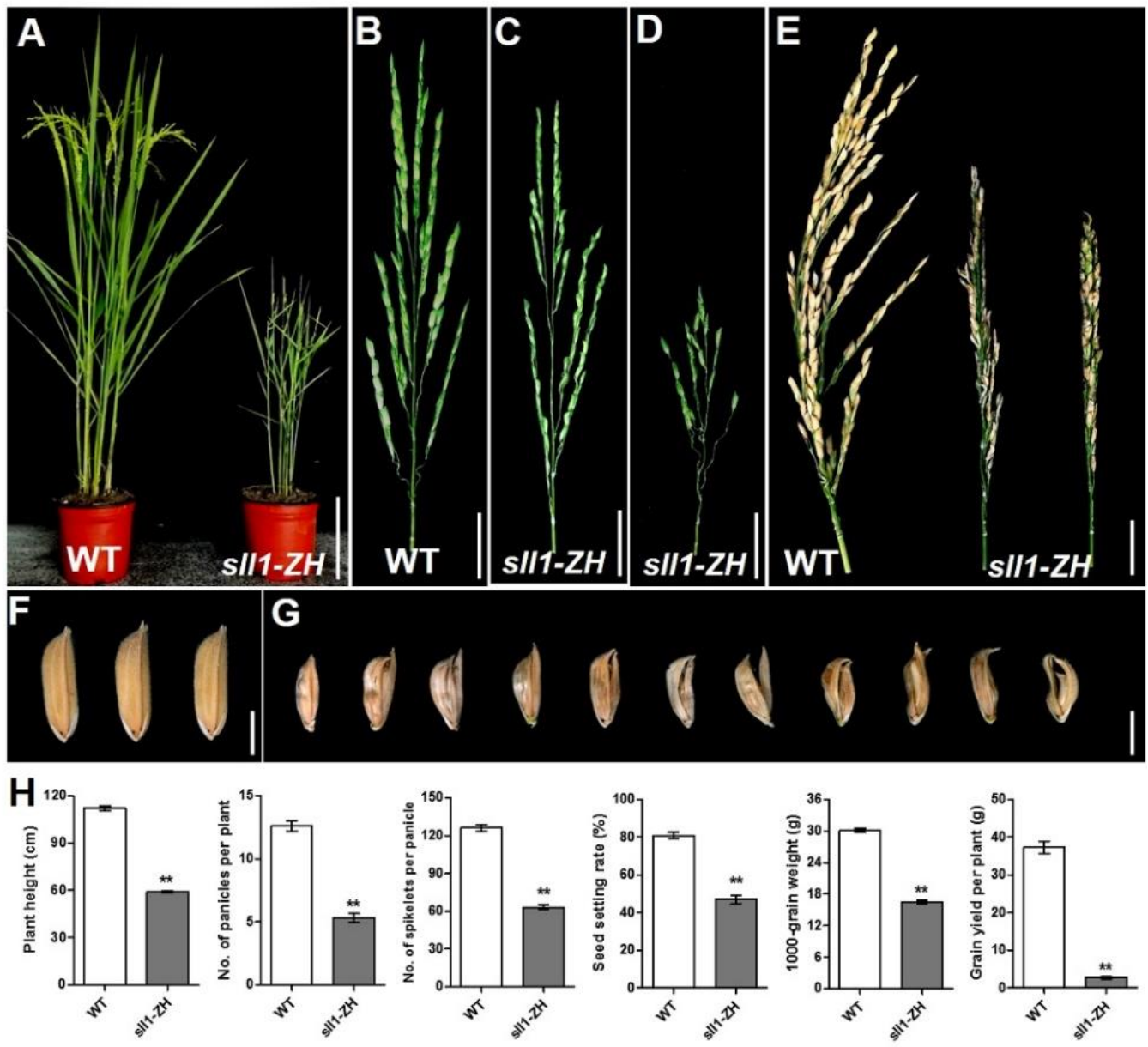

Figure 1. Phenotypic analyses of WT Zhonghui8015 (Zh8015) and the sll-ZH mutant plants. (A) Plant architecture of WT and the sll-ZH mutant at anthesis. Scale bar $=20 \mathrm{~cm}$. (B-D) Panicle architecture of WT (B) and the sll-ZH mutant (C,D) at anthesis. Scale bar $=2 \mathrm{~cm}$. (E) Panicles of WT (left) and the sll-ZH mutant (right) at maturity. Scale bar $=2 \mathrm{~cm}$. $(\mathbf{F}, \mathbf{G})$ Morphologies of grains of WT $(\mathbf{F})$ and the sll-ZH mutant $(\mathbf{G})$ at the mature stage. Scale bar $=5 \mathrm{~mm}$. $(\mathbf{H})$ Comparison of yield related agronomic traits between WT and the sll-ZH mutant. ( $n=10$ for plant height, No. of panicles per plant, No. of spikelet per panicle and seed setting rate; $n=5$ for thousand grain weight and grain yield per plant). Data represent the means \pm SD (standard deviation). The asterisks represent statistical significance determined by a Student's $t$-test ${ }^{* *}$ indicates significance at $\left.p \leq 0.01\right)$.

Table 1. Numbers of floral organs in spikelets of the WT Zh8015 and the SLL1-ZH mutant.

\begin{tabular}{|c|c|c|c|c|c|c|c|c|c|c|c|c|c|c|}
\hline \multirow{2}{*}{ Genotype } & \multirow{2}{*}{ Glumes } & \multirow{2}{*}{ Lodicules } & \multicolumn{2}{|c|}{ Lemmas/Paleas } & \multicolumn{5}{|c|}{ Stamens } & \multicolumn{3}{|c|}{ Stigmas } & \multicolumn{2}{|c|}{ Ovaries } \\
\hline & & & 2 & 3 & $\leq 3$ & 4 & 5 & 6 & $\geq 7$ & 1 & 2 & 3 & 1 & $\geq 2$ \\
\hline $\begin{array}{l}\text { Wild type } \\
\text { (200) }\end{array}$ & $\begin{array}{c}2 \\
(100 \%)\end{array}$ & $\begin{array}{c}2 \\
(100 \%)\end{array}$ & 200 & 0 & 0 & 0 & 0 & 200 & 0 & 0 & 200 & 0 & 200 & 0 \\
\hline $\begin{array}{c}\text { SLL1-ZH } \\
(400)\end{array}$ & $\begin{array}{c}2 \\
(100 \%)\end{array}$ & $\begin{array}{c}2 \\
(100 \%)\end{array}$ & 379 & 21 & 2 & 11 & 21 & 357 & 9 & 9 & 256 & 135 & 393 & 7 \\
\hline
\end{tabular}

To further observe the finer details of the morphological defects that occur during cell differentiation and development of floral organism the SLL1-ZH mutant, transverse sections and SEM of the spikelets were examined. Mature WT flowers comprised one interlocked loop constructed by one lemma and one palea with uniform cell thickness, six normal butterfly-shaped stamens with fertile pollen and two stigmas in every loculus at the top site (Figure 2N). In contrast, most paleas in the SLL1-ZH mutant were shrunken 
and invaginated and they extended into the lemma (Figure 2O-Q). The cell thicknesses of the lemmas and paleas were also altered; almost all of the paleas showed thickening (Figure $2 \mathrm{O}-\mathrm{Q}$ ), while the majority of the lemmas were thinner (Figure $2 \mathrm{O}-\mathrm{Q}$ ). The number of stamens and stigmas also varied, and the pollen grains were immature in the SLL1-ZH flowers at a similar stage (Figure $2 \mathrm{O}-\mathrm{Q}$ ). Several stamen-like fragments and structures of uncertain identity were observed in some SLL1-ZH florets (Figure 2O-Q), which was consistent with previous observations. SEM observation also revealed the uncertainty in the number of stamen primordia during the early floral organ development stages (Figure 2R-U). These morphological characteristics of floral organ identity and organ numbers suggest that the SLL1-ZH florets have acquired partial defects in lemma/palea cell proliferation, transformation defects of the inner floral organs such as stamen number, stigma-like identity, and ovary-like identity. The above results jointly proved that the SLL1$\mathrm{ZH}$ regulate not only the determination of floral organ number, but also the specification of floral organ identity in rice.

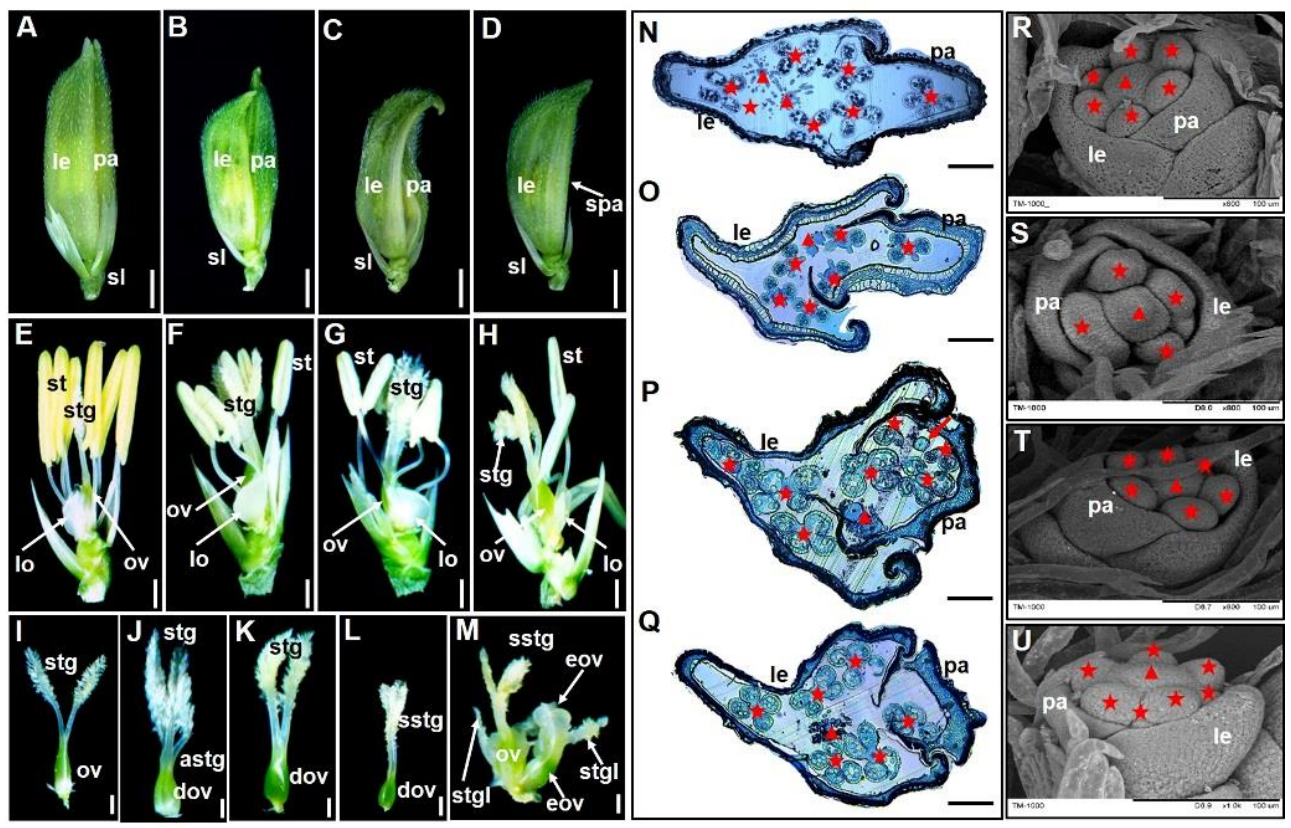

Figure 2. (A) A wild-type spikelet. (B-D) SLL1-ZH spikelets. (B) Spikelet with cracked glumes. (C) Spikelet with olecranoid lemma and invaginated palea. (D) Spikelet with shrunken palea. (E) Inner floral organs of the WT floret (F-H) SLL1-ZH florets with six stamens (F), five stamens (G), four stamens with reduced size (H). (I-L) Macrophotographs of stigmas from the florets in E-H. (M) The innermost whorls of one spikelet have extra stigma-like organs and ovary-like organs in the SLL1-ZH mutant. (N-Q) Transverse paraffin sections of spikelets from WT (N) and the SLL1-ZH mutant $(\mathbf{O}-\mathbf{Q})$. O, Thickened lemma and palea with normal number of stamens and stigmas. (P) Thine lemma and thickened palea with one ovary but seven stamens. The red arrow indicates uncertain structure. (Q) Thine lemma and thickened palea with the normal numbers of stamens and stigmas. (R-U) Scanning electron microscope (SEM) observation of early floral organ development in WT (R) and the SLL1-ZH mutant (S-U). (S) Four stamen primordium. (T) Normal six stamen primordium. (U) Seven stamen primordium. Red asterisks in (N-U) indicate the stamens, and triangles indicate the stigmas. astg, additional stigma; dov, dilated ovary; eov, extra ovary-like structure; le, lemma; lo, lodicule; ov, ovary; pa, palea; sl, sterile lemma; spa, shrunken palea; st, stamen; stg, stigma; stgl, stigma-like organ; sstg, shriveled stigma. Scale bars = $2 \mathrm{~mm}(\mathbf{A}-\mathbf{D}), 1 \mathrm{~mm}(\mathbf{E}-\mathbf{M}), 500 \mu \mathrm{m}(\mathbf{N}-\mathbf{Q})$ and $100 \mu \mathrm{m}(\mathbf{R}-\mathbf{U})$.

\subsection{Map-Based Cloning of the SLL1-ZH Mutant Gene}

Plants that displayed the SLL1-ZH phenotype in the $\mathrm{F}_{2}$ population derived from the cross $S L L 1-Z H \times 02428$ were used for gene mapping. Linkage analysis and primary 
mapping results revealed that $S L L 1-Z H$ is located in a $5.1 \mathrm{~cm}$ region on the long arm of chromosome 9, flanked by SSR loci RM24222 and RM6839 (Figure 3A). Further fine-scale mapping using 968 recessive individuals finally narrowed the position of the SLL1-ZH locus to a 30-kb region between marker loci $X-31$ and $X-22$ (Figure $3 A$ ). DNA sequencing and alignments of the three ORFs in the fine-mapping region of both WT and the SLL1-ZH mutant showed that the SLL1-ZH mutant carried a C to G at nucleotide position 104 from the ATG in the first exon of Loc_Os09g23200 (Figure 3A,B), which leads to a change in amino acid 35 (within the MYB domain of this gene) from Proline (Pro) to Leucine (Leu) (Figure 3A,B). To confirm that the C to G mutation in Loc_Os09g23200 is responsible for the malformation phenotype of SLL1-ZH mutant plants, transgenic plants expressing the WT allele $(S L L 1-Z H / C)$ were generated. The $p C O M-S L L 1-Z H$ vector was transformed into SLL1-ZH callis. The SLL1-ZH mutant phenotypes, including vegetative growth, leaf shape, floral organ structure, and seed setting rate, were almost fully rescued in the plants expressing SLL1-ZH/COM (Figure 3C). Above results demonstrated that the WT allele complemented the mutant phenotypes and that LOC_Os09g23200 is the SLL1-ZH gene.

\subsection{Transcription of SLL1-ZH and Floral Organ Development Related Factors in SLL1-ZH}

The single base pair substitution in the MYB domain of the SLL1-ZH mutant allele causes a series of defects during floral primordium differentiation and ectopic transformation. We consequently hypothesized that the sll1-ZH mutation disrupts the transcription pattern and normal function of SLL1-ZH during flower differentiation in the different floral organs. qPCR analysis results showed that the SLL1-ZH mutant had a slightly higher expression level at the SP4 stage but the transcription declined at all subsequent stages in the young inflorescences compared to the WT. At the mature spikelet stage, the SLL1-ZH expression level was decreased significantly in the lemma and stamens but increased significantly in the palea, stigmas, and ovaries (Figure 4A,B). This was consistent with the reduced floret number, thinner lemma, male sterility, thicker palea, and hyperplasia of the pistil and ovary in the SLL1-ZH mutant.

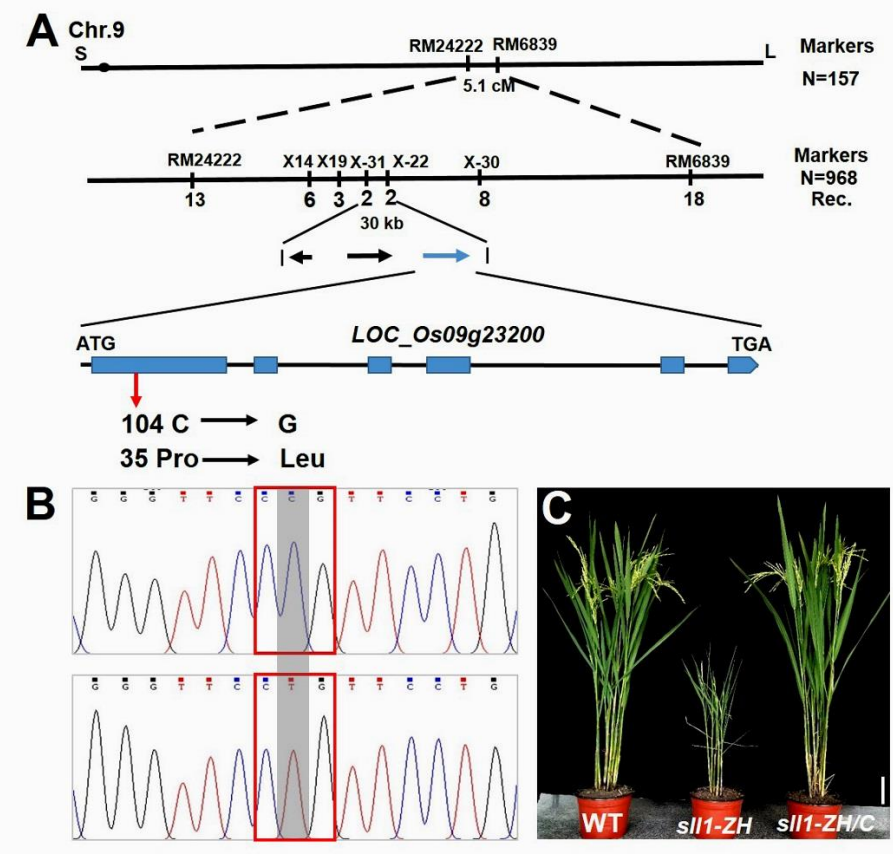

Figure 3. Map-based cloning of the SLL1-ZH gene. (A) Fine mapping and candidate gene analysis of the SLL1-ZH locus. (B) Sequencing validation of the point mutation between the WT (top) and the SLL1-ZH mutant (bottom) alleles. The red arrow indicates the position of the c nucleotide mutation in SLL1-ZH. (C) Characterization of the complemented transgenic plant compared to WT and the mutant. Scale bar $=20 \mathrm{~cm}$. 
Further transcriptional analysis of floral organ identity genes reflected similar trends. The expression level of four genes, DFO1, DL, OsMADS14, and OsMADS15, showed a transient increase at the Sp6 stage and decreased at all other stages during early floral organ development. The other six genes were down-regulated at all stages (Figure 4A). However, the relative expression levels of the assayed genes in mature flower organs showed some difference. All these genes showed significantly lower expression levels in the lemma. The expression levels of DFO1 and OSPEX5 were significantly increased, but expression of $D L$, OsMADS1, OsMADS14, and OsMADS32 was significantly decreased in the palea. In stamens, only DFO1 and OsMADS14 showed the same significant down-regulation, while $D L$, OsMADS1, OsMADS15, and OsMADS32 were unexpectedly up-regulated. In stigmas, $D L$ and OsMADS1 showed significantly reduced expression, but other genes including DFO1, OsPEX5, OsMADS6, OsMADS15, and OsMADS16 were up-regulated like SLL1-ZH. Interestingly, all off the assayed genes were significantly up-regulated in the ovary except for OsMADS6. Altogether, the above results demonstrate the critical role of SLL1-ZH in rice floral organ development, and that loss of function of SLL1-ZH in the mutant significantly affected the transcription level of genes related to flower organ identity and development.
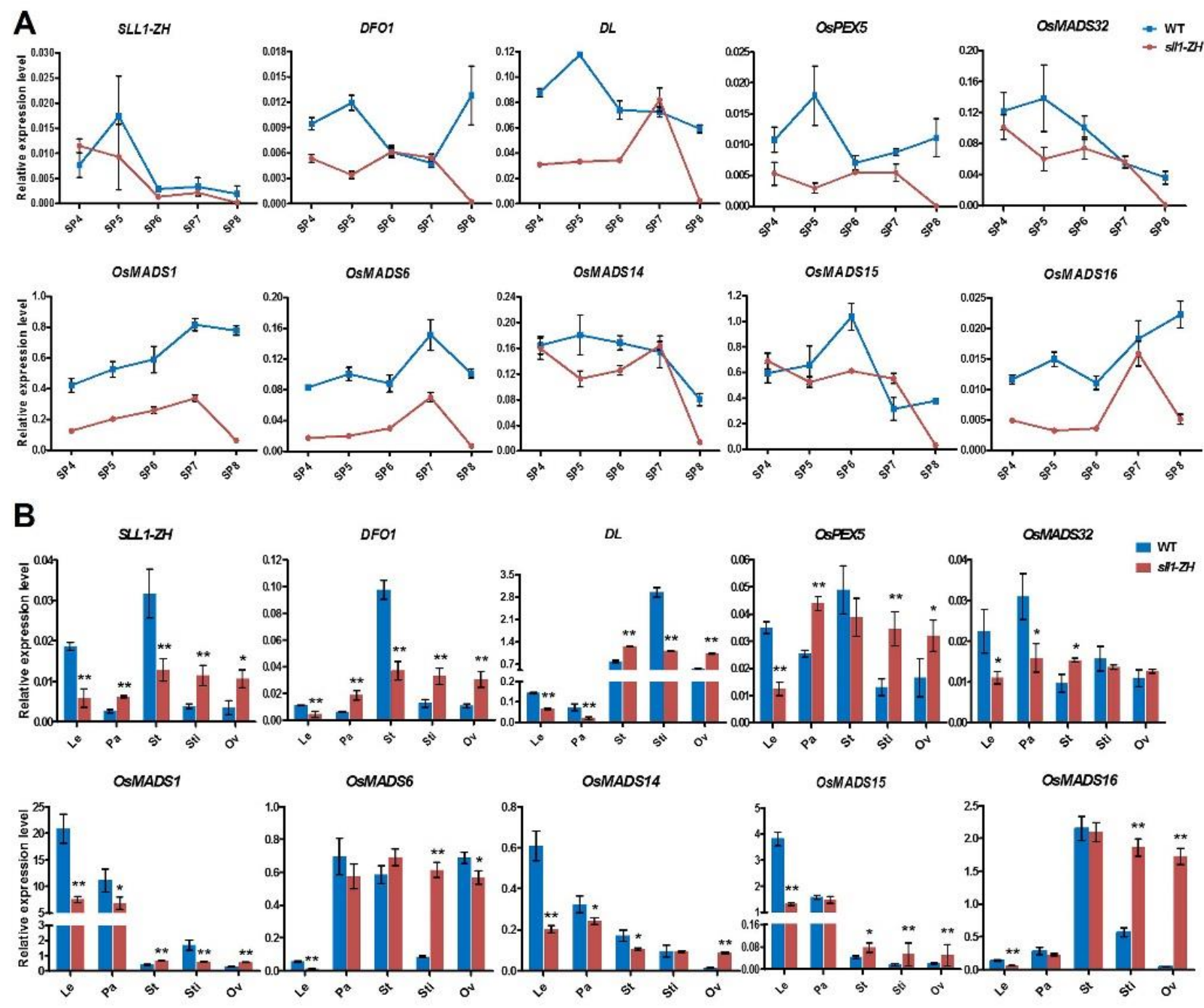

Figure 4. Transcription analysis of rice floral organ development factors in WT and the SLL1-ZH mutant. (A) Relative expression levels of floral organ identity genes in young inflorescences at different development stages in the WT and SLL1-ZH mutant. (B) Relative expression levels of related genes in the different floral organs in mature spikelets in the WT and SLL1-ZH mutant. Error bars show the SD $(n=3)$. Student's t-test was used for the statistical analysis $\left({ }^{*}\right.$ and ${ }^{* *}$ indicates significant difference at the $p<0.05$ and $p<0.01$ level, respectively). Le, lemma; Ov, ovary; Pa, palea; St, stamen; Sti, stigma. 


\section{Discussion}

The development of the florets structure directly determines spikelet fertility and grain yield in rice. Therefore, studies on floral organ development-related mutants and related genes that regulate floral architecture are of critical importance for understanding not only the theoretical molecular mechanism and developmental biology in rice and other plants, but also for providing gene resources for molecular design breeding and genetic improvement of rice cultivars. In this study, we isolated a novel allelic mutant of sll that displayed a semi-dwarf phenotype, rolled leaves, abnormal florets, and low grain yield. The results presented here provide more comprehensive evidence for the complex and multifaceted function of MYB genes in regulating rice reproductive development and grain yield formation.

The SLL1-ZH mutant characterized in this study carries a novel allele of SLL1/AH2 isolated from our EMS mutagenesis population of the indica rice cultivar Zh8015. The mutant plants exhibited both a weak growth state and abnormal floral organ development. The sll1-ZH mutant shares the rolled leaf trait with sll1-1 and sll1-2 and has deformed spikelets similar to the ah2 mutant, which revealed the complex function of the MYB gene SLL1/AH2 in regulating rice growth $[43,44]$. Novel defects were also observed in the SLL1-ZH mutant, such as a variable number of stamens and stigmas, proliferative, and ectopic ovaries and multiple grain morphologies. These finding suggest the additional functions of SLL1/AH2 in regulating inner floral organ number and identity in rice. Sequence analysis showed that SLL1-ZH has a single base substitution (C to $G$ ) in the MYB domain region which results in a corresponding amino acid change in the protein sequence (Figure $3 \mathrm{~A}, \mathrm{~B}$ ). Both of the sll1 mutants are in the japonica background with a $\mathrm{G}$ to $\mathrm{A}$ substitution in the intron splicing site, which caused mRNA splicing and premature termination of translation [43]. The defective spikelets of $a h 2$ are caused by a single $C$ to T mutation in the fifth exon of the gene, which resulted in a premature translation stop in the indica variety SKZ [44]. It is possible that such multiple and serious deformities in SLL1-ZH mutant plants could be caused by a stronger nucleotide mutation in the $5^{\prime}$ region of the MYB gene SLL1/AH2 than the other allelic mutants previously reported allelic mutants. This further shows that the diversified function of the SLL1 / AH2 gene in determining rice growth and floret development.

$S L L 1 / A H 2$ has been reported to regulate not only sclerenchymatous cell formation and leaf rolling, but also glume structure development, palea identity, and grain shape [43,44]. Related phenotypes were all observed in our SLL1-ZH mutant; moreover, the plants had semi-dwarf stature and deformed inner floral organs. Actually, almost all of the floral organs in the SLL1-ZH mutant appeared to display varying degrees of developmental defects except for the sterile glumes and lodicules. Distortion of the palea and lemma made most of the mutant seeds smaller, shorter, and exposed to the air, resulting in not only a decreased grain yield, but also poor grain quality and a high probability of mildew in the mutant. Factors such as a short stem, fewer tillers, and low seed setting rate also aggravate the low grain yield in the mutant. In addition, the low seed setting rate was partly due to deformed development of the internal flower organs, such as immature stamens and pollen grains, shrunken stigmas, and ectopia ovaries, which blocked normal pollination. In addition, the loss of function of SLL1-ZH in the mutant resulted in significant changes in the expression patterns of SLL1-ZH and a series of floral organ identity-related genes. The transcription levels of almost all tested floret development-related genes were decreased during early inflorescence differentiation, suggesting that the process of spikelet primordium formation had encountered great catastrophe. The mRNA levels of SLL1$\mathrm{ZH}$ and flower development-related genes were even altered in mature floral organs in the SLL1-ZH mutant. These results further demonstrate that the normal function of the $S L L 1 / A H 2$ gene is of great significance in rice yield formation.

A surprising discovery also broadens our understanding of how the SLL1/AH2 gene regulates rice floral organ identity development. First, we found that most of the lemmas became thinner, although the palea was thicker than in WT, and the expression level of SLL1-ZH was also significantly reduced in the WT lemma but was up-regulated in 
the SLL1-ZH mutant. All detected marker genes involved in determining floral organ identity and development showed the same down-regulated expression. However, only DFO1 and OsPEX5 were the same up-regulated in the mutant. The expression levels of transcription factors genes such as DL, OsMADS1, OsMADS14, and OsMADS32 were all significantly decreased in the palea (Figure $4 \mathrm{~B}$ ), indicating that there is a different regulation relationship between SLL1-ZH and these genes in controlling palea differentiation and cell proliferation. Second, decreased expression level of SLL1-ZH, DFO1, and OsMADS14 and abnormal up-regulation of DL, OsMADS1, OsMADS15, and OsMADS32 together caused variable numbers of stamens and immature pollen grains (Figures $2 \mathrm{~F}-\mathrm{H}, \mathrm{O}-\mathrm{Q}$ and $4 \mathrm{~B}$ ). Furthermore, the SLL1-ZH mutant had many hyperplastic but shrunken stigmas and ovaries. The transparent ovule-like cell clusters along with the multiple stigmas-like and ovary-like organs, resulted in confused and indistinguishable identity of internal flower organ structures in the SLL1-ZH mutant (Figure 2H,L,M,P). In addition, the expression level of SLL1-ZH and many related genes, particularly the B-class regulators DL and OsMADS16 that specify the identities of the stamen, stigma and carpel $[16,18]$, were all altered in the mutant (Figure 4B). The construction and phenotypic analysis of related double/multiple mutants is urgently needed for verification of the interaction between SLL1/AH2 and these genes. All of the above results indicated that the function of the MYB transcription factor SLL1/AH2 may not be limited to the glume (lemma and palea) and grain yield. Regulation of the number and identities of internal flower organs are also of great importance for normal growth in rice, and this cannot be ignored.

\section{Conclusions}

The results of this study provide strong evidence that SLL1-ZH affects not only grain yield formation and glume development, but also internal floral organs number and development in rice.

Supplementary Materials: The following are available online at https:/ /www.mdpi.com/article/ 10.3390/agriculture11111162/s1, Figure S1: Characterization of leaf in the wild-type and SLL1-ZH mutant, Table S1: Segregation analysis of the SLL1-ZH allele, Table S2: Candidate genes in the fine-mapping region of SLL1-ZH locus, Table S3: Primers and purpose used in this study.

Author Contributions: Conceptualization, X.Z. and L.S.; methodology, L.S. and J.W.; validation, L.S., J.W., and X.W.; investigation, L.S., J.W., and Z.P.; resources, Y.Z., L.S., S.C., and L.C.; data curation, D.C. and X.W.; writing — original draft preparation, L.S.; writing—review and editing, S.C., L.C., Y.Z., and X.Z.; visualization, L.S.; supervision, S.C., L.C., Y.Z., and L.S.; project administration, L.S., S.C., L.C., and X.Z.; funding acquisition, L.S., S.C., L.C., and X.Z. All authors have read and agreed to the published version of the manuscript.

Funding: This research was partially supported by the Natural Science Foundation of Zhejiang Province of China (Grant No. LY21C130003, LY17C130003), the Zhejiang Provincial Key Special Projects (Grant No. 2021C02063-1), National Natural Science Foundation of China (Grant No. 31801440, 31961143016), the Agricultural Science and Technology Innovation Program of the Chinese Academy of Agricultural Science (Grant No. CAAS-ASTIP-2013-CNRRI) and the China Postdoctoral Science Foundation (Grant No. 2018M631641).

Institutional Review Board Statement: Not applicable.

Informed Consent Statement: Not applicable.

Data Availability Statement: The datasets used or analyzed in the present study are available upon demand from the corresponding author.

Conflicts of Interest: The authors declare no conflict of interest. 


\section{References}

1. Bommert, P.; Satoh-Nagasawa, N.; Jackson, D.; Hirano, A.H. Genetics and evolution of inflorescence and flower development in grasses. Plant Cell Physiol. 2005, 46, 69-78. [CrossRef]

2. Itoh, J.; Nonomura, K.; Ikeda, K.; Yamaki, S.; Inukai, Y.; Yamagishi, H.; Kitano, H.; Nagato, A.Y. Rice plant development: From zygote to spikelet. Plant Cell Physiol. 2005, 46, 23-47. [CrossRef]

3. Yoshida, H.; Nagato, A.Y. Flower development in rice. J. Exp. Bot. 2011, 62, 4719-4730. [CrossRef] [PubMed]

4. Coen, E.S.; Meyerowitz, E.M. The war of the whorls: Genetic interactions controlling flower development. Nature 1991, 353, 31-37. [CrossRef]

5. Colombo, L.; Franken, J.; Koetje, E.; van Went, J.; Dons, H.J.; Angenent, G.C.; van Tunen, A.J. The petunia MADS box gene FBP11 determines ovule identity. Plant Cell 1995, 7, 1859-1868.

6. Ditta, G.; Pinyopich, A.; Robles, P.; Pelaz, S.; Yanofsky, M.F. The SEP4 gene of Arabidopsis thaliana functions in floral organ and meristem identity. Curr. Biol. 2004, 14, 1935-1940. [CrossRef] [PubMed]

7. Ferrario, S.; Immink, R.G.; Shchennikova, A.; Busscher-Lange, J.; Angenent, G.C. The MADS box gene FBP2 is required for SEPALLATA function in petunia. Plant Cell 2003, 15, 914-925. [CrossRef] [PubMed]

8. Mandel, M.A.; Yanofsky, M.F. The Arabidopsis AGL8 MADS box gene is expressed in inflorescence meristems and is negatively regulated by APETALA1. Plant Cell 1995, 7, 1763-1771. [PubMed]

9. Lamb, R.S.; Irish, V.F. Functional divergence within the APETALA3/PISTILLATA floral homeotic gene lineages. Proc. Natl. Acad. Sci. USA 2003, 100, 6558-6563. [CrossRef]

10. Fornara, F.; Parenicová, L.; Falasca, G.; Pelucchi, N.; Masiero, S.; Ciannamea, S.; Lopez-Dee, Z.; Altamura, M.M.; Colombo, L.; Kater, M.M. Functional characterization of OsMADS18, a member of the AP1/SQUA subfamily of MADS box genes. Plant Physiol. 2004, 135, 2207-2219. [CrossRef] [PubMed]

11. Jeon, J.S.; Jang, S.; Lee, S.; Nam, J.; Kim, C.; Lee, S.H.; Chung, Y.Y.; Kim, S.R.; Lee, Y.H.; Cho, Y.G.; et al. Leafy hull sterile1 Is a homeotic mutation in a rice MADS box gene affecting rice flower development. Plant Cell 2000, 12, 871-884. [CrossRef] [PubMed]

12. Kobayashi, K.; Yasuno, N.; Sato, Y.; Yoda, M.; Yamazaki, R.; Kimizu, M.; Yoshida, H.; Nagamura, Y.; Kyozuka, J. Inflorescence meristem identity in rice is specified by overlapping functions of three AP1/FUL-like MADS box genes and PAP2, a SEPALLATA MADS box gene. Plant Cell 2012, 24, 1848-1859. [CrossRef]

13. Lu, S.J.; Wei, H.; Wang, Y.; Wang, H.M.; Yang, R.F.; Zhang, X.B.; Tu, J.M. Overexpression of a transcription factor OsMADS15 modifies plant architecture and flowering time in rice (Oryza sativa L.). Plant Mol. Biol. Rep. 2012, 30, 1461-1469. [CrossRef]

14. Sentoku, N.; Kato, H.; Kitano, H.; Imai, R. OsMADS22, an STMADS11-like MADS-box gene of rice, is expressed in non-vegetative tissues and its ectopic expression induces spikelet meristem indeterminacy. Mol. Genet. Genom. 2005, 273, 1-9. [CrossRef] [PubMed]

15. Wang, H.; Zhang, L.; Cai, Q.; Hu, Y.; Jin, Z.; Zhao, X.; Fan, W.; Huang, Q.; Luo, Z.; Chen, M.; et al. OsMADS32 interacts with PI-like proteins and regulates rice flower development. J. Integr. Plant Biol. 2015, 57, 504-513. [CrossRef]

16. Nagasawa, N.; MiyOshi, M.; Sano, Y.; Satoh, H.; Hirano, H.; Sakai, H.; Nagato, Y. SUPERWOMAN1 and DROOPING LEAF Genes control floral organ identity in rice. Development 2003, 130, 705-718. [CrossRef]

17. Xiao, H.; Wang, Y.; Liu, D.F.; Wang, W.M.; Li, X.B.; Zhao, X.F.; Xu, J.C.; Zhai, W.X.; Zhu, L.H. Functional analysis of the rice AP3 homologue OsMADS16 by RNA interference. Plant Mol. Biol. 2003, 52, 957-966. [CrossRef]

18. Li, H.F.; Liang, W.Q.; Hu, Y.; Zhu, L.; Yin, C.S.; Xu, J.; Dreni, L.; Kater, M.M.; Zhang, D.B. Rice MADS6 interacts with the floral homeotic genes SUPERWOMAN1, MADS3, MADS58, MADS13, and DROOPING LEAF in specifying floral organ identities and meristem fate. Plant Cell 2011, 23, 2536-2552. [CrossRef]

19. Yamaguchi, T.; Lee, D.Y.; Miyao, A.; Hirochika, H.; An, G.; Hirano, H.Y. Functional diversification of the two C-class MADS box genes OsMADS3 and OsMADS58 in Oryza sativa. Plant Cell 2006, 18, 15-18. [CrossRef]

20. Dreni, L.; Jacchia, S.; Fornara, F.; Fornari, M.; Ouwerkerk, P.B.; An, G.; Colombo, L.; Kater, M.M. The D-lineage MADS-box gene OsMADS13 controls ovule identity in rice. Plant J. 2007, 52, 690-699. [CrossRef]

21. Dreni, L.; Pilatone, A.; Yun, D.; Erreni, S.; Pajoro, A.; Caporali, E.; Zhang, D.B.; Kater, M.M. Functional analysis of all AGAMOUS subfamily members in rice reveals their roles in reproductive organ identity determination and meristem determinacy. Plant Cell 2011, 23, 2850-2863. [CrossRef]

22. Cui, R.F.; Han, J.K.; Zhao, S.Z.; Su, K.M.; Wu, F.; Du, X.Q.; Xu, Q.J.; Chong, K.; Theissen, G.; Meng, Z. Functional conservation and diversification of class E floral homeotic genes in rice (Oryza sativa). Plant J. 2010, 61, 767-781. [CrossRef]

23. Jeon, J.S.; Lee, S.; Jung, K.H.; Yang, W.S.; Yi, G.H.; Oh, B.G.; An, G. Production of transgenic rice plants showing reduced heading date and plant height by ectopic expression of rice MADS-box genes. Mol. Breed. 2000, 6, 581-592. [CrossRef]

24. Khanday, I.; Yadav, S.R.; Vijayraghavan, U. Rice LHS1/OsMADS1 controls floret meristem specification by coordinated regulation of transcription factors and hormone signaling pathways. Plant Physiol. 2013, 161, 1970-1983. [CrossRef]

25. Prasad, K.; Parameswaran, S.; Vijayraghavan, U. OsMADS1, a rice MADS-box factor, controls differentiation of specific cell types in the lemma and palea and is an early-acting regulator of inner floral organs. Plant J. 2005, 43, 915-928. [CrossRef] [PubMed]

26. Sun, L.P.; Zhang, Y.X.; Zhang, P.P.; Yang, Z.F.; Zhan, X.D.; Shen, X.H.; Zhang, Z.H.; Hu, X.; Xuan, D.D.; Wu, W.X.; et al. K-domain splicing factor OsMADS1 regulates open hull male sterility in rice. Rice Sci. 2015, 22, 207-216.

27. Yamaguchi, T.; Nagasawa, N.; Kawasaki, S.; Matsuoka, M.; Nagato, Y.; Hirano, H.Y. The YABBY gene DROOPING LEAF regulates carpel specification and midrib development in Oryza sativa. Plant Cell 2004, 16, 500-509. [CrossRef] [PubMed] 
28. Chu, H.W.; Qian, Q.; Liang, W.Q.; Yin, C.S.; Tan, H.X.; Yao, X.; Yuan, Z.; Yang, J.; Huang, H.; Luo, D.; et al. The floral organ number4 gene encoding a putative ortholog of Arabidopsis CLAVATA3 regulates apical meristem size in rice. Plant Physiol. 2006, 142, 1039-1052. [CrossRef] [PubMed]

29. Moon, S.; Jung, K.H.; Lee, D.E.; Lee, D.Y.; Lee, J.; An, K.; Kang, H.G.; An, G. The rice FON1 gene controls vegetative and reproductive development by regulating shoot apical meristem size. Mol. Cells 2006, 21, 147-152.

30. Suzaki, T.; Sato, M.; Ashikari, M.; Miyoshi, M.; Nagato, Y.; Hirano, H.Y. The gene FLORAL ORGAN NUMBER1 regulates floral meristem size in rice and encodes a leucine-rich repeat receptor kinase orthologous to Arabidopsis CLAVATA1. Development 2004, 131, 5649-5657. [CrossRef] [PubMed]

31. Suzaki, T.; Toriba, T.; Fujimoto, M.; Tsutsumi, N.; Kitano, H.; Hirano, H.Y. Conservation and diversification of meristem maintenance mechanism in Oryza sativa: Function of the FLORALORGAN NUMBER2 gene. Plant Cell Physiol. 2006, 47, 1591-1602. [CrossRef]

32. Yan, D.W.; Zhang, X.M.; Zhang, L.; Ye, S.H.; Zeng, L.J.; Liu, J.Y.; Li, Q.; He, Z.H. CURVED CHIMERIC PALEA 1 encoding an EMF1-like protein maintains epigenetic repression of OsMADS58 in rice palea development. Plant J. 2015, 82, 12-24. [CrossRef]

33. Zheng, M.; Wang, Y.H.; Wang, Y.L.; Wang, C.M.; Ren, Y.L.; Lv, J.; Peng, C.; Wu, T.; Liu, K.; Zhao, S.L.; et al. DEFORMED FLORAL ORGAN1 (DFO1) regulates floral organ identity by epigenetically repressing the expression of OsMADS58 in rice (Oryza sativa). New Phytol. 2015, 206, 1476-1490. [CrossRef]

34. Tao, J.H.; Liang, W.Q.; An, G.; Zhang, D.B. OsMADS6 Controls Flower Development by Activating Rice FACTOR OF DNA METHYLATION LIKE1. Plant Physiol. 2018, 177, 713-727. [CrossRef]

35. You, X.M.; Zhu, S.S.; Zhang, W.W.; Zhang, J.; Wang, C.M.; Jing, R.N.; Chen, W.W.; Wu, H.M.; Cai, Y.; Feng, Z.M.; et al. OsPEX5 regulates rice spikelet development through modulating jasmonic acid biosynthesis. New Phytol. 2019, 224, 712-724. [CrossRef]

36. Zhuang, H.; Wang, H.L.; Zhang, T.; Zeng, X.Q.; Chen, H.; Wang, Z.W.; Zhang, J.; Zheng, H.; Tang, J.; Ling, Y.H.; et al. NONSTOP GLUMES1 Encodes a C2H2 zinc finger protein that regulates spikelet development in rice. Plant Cell 2020, 32, 392-413. [CrossRef]

37. He, Y.B.; Yan, L.; Ge, C.N.; Yao, X.F.; Han, X.; Wang, R.C.; Xiong, L.Z.; Jiang, L.W.; Liu, C.M.; Zhao, Y.D. PINOID is required for formation of the stigma and style in rice. Plant Physiol. 2019, 180, 926-936. [CrossRef]

38. Xu, M.; Tang, D.; Cheng, X.J.; Zhang, J.X.; Tang, Y.J.; Tao, Q.D.; Shi, W.Q.; You, A.Q.; Gu, M.H.; Cheng, Z.K.; et al. OsPINOID regulates stigma and ovule initiation through maintenance of the floral meristem by auxin signaling. Plant Physiol. 2019, 180, 952-965. [CrossRef] [PubMed]

39. Wu, M.H.; Xie, D.J.; Tang, Z.S.; Shi, D.Q.; Yang, W.C. PINOID regulates floral organ development by modulating auxin transport and interacts with MADS16 in rice. Plant Biotechnol. J. 2020, 18, 1778-1795. [CrossRef] [PubMed]

40. Li, H.P.; Li, H.; Liu, Z.J.; Zhuang, Y.; Wei, M.; Gu, Y.Y.; Liu, Y.X.; Sun, X.Q.; Tang, Y.Y.; Yue, L.; et al. Characterization of the 'Oat-Like Rice' caused by a novel allele OsMADS1 ${ }^{\mathrm{Olr}}$ reveals vital importance of OsMADS1 in regulating grain shape in Oryza sativa L. Rice 2020, 13, 73. [CrossRef] [PubMed]

41. Zhang, Y.; Yu, H.P.; Liu, J.; Wang, W.; Sun, J.; Gao, Q.; Zhang, Y.H.; Ma, D.R.; Wang, J.Y.; Xu, Z.J.; et al. Loss of function of OsMADS34 leads to large sterile lemma and low grain yield in rice (Oryza sativa L.). Mol. Breed. 2016, 36, 147. [CrossRef]

42. Ma, X.D.; Zhang, J.N.; Han, B.; Tang, J.H.; Cui, D.; Han, L.Z. FLA, which encodes a homolog of UBP, is required for chlorophyll accumulation and development of lemma and palea in rice. Plant Cell Rep. 2019, 38, 321-331. [CrossRef]

43. Zhang, G.H.; Xu, Q.; Zhu, X.D.; Qian, Q.; Xue, H.W. SHALLOT-LIKE1 is a KANADI transcription factor that modulates rice leaf rolling by regulating leaf abaxial cell development. Plant Cell 2009, 21, 719-735. [CrossRef] [PubMed]

44. Ren, D.Y.; Cui, Y.J.; Hu, H.T.; Xu, Q.K.; Rao, Y.C.; Yu, X.Q.; Zhang, Y.; Wang, Y.X.; Peng, Y.L.; Zeng, D.L.; et al. AH2 encodes a MYB domain protein that determines hull fate and affects grain yield and quality in rice. Plant J. 2019, 100, 813-824. [CrossRef]

45. Yan, D.W.; Zhou, Y.; Ye, S.H.; Zeng, L.J.; Zhang, X.M.; He, Z.H. BEAK-SHAPED GRAIN 1/TRIANGULAR HULL 1, a DUF640 gene, is associated with grain shape, size and weight in rice. Sci. China Life Sci. 2013, 56, 275-283. [CrossRef]

46. Wei, X.J.; Zhang, X.W.; Shao, G.N.; He, J.W.; Jiao, G.A.; Xie, L.H.; Sheng, Z.H.; Tang, S.Q.; Hu, P.S. Fine mapping of BH1, a gene controlling lemma and palea development in rice. Plant Cell Rep. 2013, 32, 1455-1463. [CrossRef] [PubMed]

47. Ren, D.Y.; Rao, Y.C.; Wu, L.W.; Xu, Q.K.; Li, Z.Z.; Yu, H.P.; Zhang, Y.; Leng, Y.J.; Hu, J.; Zhu, L.; et al. The pleiotropic $A B N O R M A L$ FLOWER AND DWARF1 affects plant height, floral development and grain yield in rice. J. Integr. Plant Biol. 2016, 58, 529-539. [CrossRef]

48. Zhang, T.; Li, Y.F.; Ma, L.; Sang, X.C.; Ling, Y.H.; Wang, Y.T.; Yu, P.; Zhuang, H.; Huang, J.Y.; Wang, N.; et al. LATERAL FLORET 1 induced the three-florets spikelet in rice. Proc. Natl. Acad. Sci. USA 2017, 114, 9984-9989. [CrossRef] [PubMed]

49. Li, H.G.; Xue, D.W.; Gao, Z.Y.; Yan, M.X.; Xu, W.Y.; Xing, Z.; Huang, D.N.; Qian, Q.; Xue, Y.B. A putative lipase gene EXTRA GLUME1 regulates both empty-glume fate and spikelet development in rice. Plant J. 2009, 57, 593-605. [CrossRef]

50. Ren, D.Y.; Yu, H.P.; Rao, Y.C.; Xu, Q.K.; Zhou, T.T.; Hu, J.; Zhang, Y.; Zhang, G.H.; Zhu, L.; Gao, Z.Y.; et al. 'Two-floret spikelet' as a novel resource has the potential to increase rice yield. Plant Biot. J. 2018, 16, 351-353. [CrossRef]

51. Sun, L.P.; Xiang, X.J.; Yang, Z.F.; Yu, P.; Wen, X.X.; Wang, H.; Adil, A.; Riaz, M.K.; Zhang, Y.X.; Cheng, S.H.; et al. OsGPAT3 plays a critical role in anther wall programmed cell death and pollen development in rice. Int. J. Mol. Sci. 2018, 19, 4017. [CrossRef] [PubMed] 
52. Sun, L.P.; Zhang, Y.X.; Zhang, P.P.; Yang, Z.F.; Zhou, X.X.; Xuan, D.D.; Li, Z.H.; Wu, W.X.; Zhan, X.D.; Shen, X.H.; et al. Morphogenesis and Gene Mapping of deformed interior floral organ 1 (difo1), a novel mutant associated with floral organ development in rice. Plant Mol. Biol. Rep. 2017, 35, 330-344. [CrossRef]

53. Schmittgen, T.D.; Livak, K.J. Analyzing real-time PCR data by the comparative C (T) method. Nat. Protoc. 2008, 3, 1101-1108. [CrossRef] [PubMed] 